\title{
LA LITERATURA EN LA
}

\section{ENSEÑANZA DEL ALEMÁN COMO LENGUA EXTRANJERA}

\author{
Manuel Maldonado Alemán - Univ. de Sevilla \\ julia M. Borreguero Beltrán - E.O.I. Huelva
}

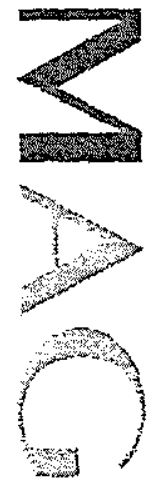

a utilización del texto literario en la enseñanza del alemán como lengua extranjera se enfrenta desde un principio a un conjunto de dificultades. Particularmente, el contexto cultural e histórico y el código lingüístico del texto son elementos extraños al lector/alumno que dificultan la actividad comprensiva.

En estos casos, el alumno se encuentra por lo general frente a un texto con el que no está familiarizado, que se caracteriza por su complejidad y autenticidad en cuanto a las estructuras fonológicas, morfológicas, sintácticas y léxicas que lo componen, y que tendrá que constituir primeramente en texto, 0 sea, reconocer su estructura lingüistico/textual convencional, antes de que pueda adentrarse en su comprensión.

Junto a esa diferencia lingüística se da al mismo tiempo una diferencia intercultural, por cuanto con el texto literario cada lector "erhält ein doppeltes Angebot: sich selbst darin zu finden und einen Ausdruck der Gesellschaft, worin der Text entstanden ist"'. El trasfondo histórico y sociocultural, por regla general desconocido para el alumno, asi como las presuposiciones y connotaciones que éste entraña, representan un importante obstáculo que obligará a la realización de una lectura lenta y precisa, en cuyo transcurso el receptor tratará de encontrar respuesta a difererentes cuestiones que plantean tanto el texto como su contexto. En este sentido se puede afirmar que la comprensión de un texto en lengua extranjera "ist ein gesteigerter Fall problematisch gewordenen Verstehens und zwingt den muttersprachigen Leser/Interpreten auf die eigenen Verstehensvoraussetzungen zu reflektieren"2.

$Y$ a pesar de estas dificultades, pero también debido a ellas, consideramos que el texto literario es un medio idóneo para la enseñanza del alemán como lengua extranjera, también en los primeros niveles. Su utilidad didáctica es especialmente importante no sólo porque permite la presentación de fenómenos culturales (literarios) y lingüisticos en su auténtica complejidad y uso real, y contribuye asi a desarrollar en el receptor su capacidad cognoscitiva y competencia lectora; sino también porque este tipo de textos suele provocar en el alumno una predisposición emocional y un interés afectivo hacia el aprendizaje de la lengua extranjera, lo que es considerado por la psicolingüistica de suma importancia para una enseñanza eficaz $z^{j}$.

La literatura puede contribuir, entre otros aspectos, al descubrimiento de la auténtica alteridad de la lengua extranjera y de su cultura, a la esti-

\footnotetext{
'D. Krusche, Auischiuß. Kurze deutsche Prosa im Unterricht Deutsch als Fremdsprache. Teil II: Erläuterungen und Mlaterialien, Bonn, Inter Nationes, $4^{\mathrm{a}}$ ed., 1991, pàg. 5.

'S. Ehlers, "Perspektivenwahrnenmung. Aspekte fremokultureilen Verstenens und seiner Förderung im Literaturunterricht", en jahrizush der Deutschdidaktik, (1989/90), pżgs. 132-152, aqui pàg. 143. Vid. tambiën H. Hunfeld, Literatur als Sprachleinre. Ansëize eines herma-
} neutisch orientierten Fremdsprachenunterrichts. Berlin, 1990.

: Vid. R. Ellis, Understanding Seccnd Language Acquisi:ion, Oxicrd, Oxiord University Press, i985, päg. 122. 
mulación de ụn aprendizaje efectivamente intercultural, a la ampliación de la competencia comunicativa mediante el uso connotativo de la lengua, al fomento de la expresión libre y creativa, e incluso literaria, a la reflexión sobre los mecanismos comprensivos y también sobre la propia alteridad, etc.

Pero centrar la enseñanza del alemán como lengua extranjera en el texto literario implica, desde nuestra perspectiva, superar los modelos didácticos orientados en el estructuralismo y en la gramática generativa que, al fundamentarse en una concepción inmanentista de los fenómenos lingüisticos, desligan la lengua de su uso concreto y contextualizado, y niegan que el significado sea una categoria propia del sujeto. Esos modelos, basados en la 'lingüistica de la frase', centran la enseñanza de la lengua

en una transmisión de estructuras y relaciones lingüisticas prefijadas por un sistema universal y abstracto, y conciben al alumno como un mero receptor pasivo de los conocimientos transmitidos. El saber, desde esta concepción, nunca es un saber construido, sino transferido e incluso impuesto. $Y$ el lenguaje es ante todo un sistema de signos portadores por si mismos de significado.

La superación docente de este inmanentismo requiere, a nuestro entender, tanto la aclaración previa de la función que corresponde al alumno en el proceso de enseñanza-aprendizaje y de su grado de implicación en él, por una parte; como también, por otra, la dilucidación de las vias que han de facilitarle el acceso al conocimiento lingüistico-literario.

A este respecto se comprueba que la pragmática y la teoria de la literatura, al igual que otras disciplinas que en lasúltimas décadas se vienen ocupando del problema de la comprensión textual, particularmente la lingüística del texto, la psicologia cognitiva y la psicolingüistica*, han llegado en la actualidad por lo general a la conclusión de que el lenguaje, antes que ser un sistema denotativo de signos, es un sistema de acciones y operaciones, un instrumento comunicativo que sólo puede existir en su uso e inmerso en un proceso constante de construcción de sentido. $Y$ sus usuarios nunca son seres abstractos, homogéneos o 'ideales', "sino miembros de comunidades basadas en la desigualdad y en la diversidad"5, con caracteristicas socioculturales y psicológicas bien definidas $e$ individualizadas. Por esa razón, "hablar una lengua no es sólo conocer las reglas del lenguaje sino saber usarla de forma adecuada en sus contextos de producción y recepción" ${ }^{\prime 6}$.

Por eso mismo se entiende que la comprensión de un texto, también del literario, es un proceso activo de elaboración y construcción de sentido. Antes que ser una cualidad inherente al texto, intemporal e inmutable, el sentido textual es una categoria eminentemente comunicativa, perteneciente al ámbito cognitivo del receptor o intérprete, en la que inter-

\footnotetext{
- Vid., a modo de ejemplo, S. C. Levinson, Pragmatik, Tübingen, Niemeyer, $2^{\mathbf{a}}$ ed., 1994. G. Reyes, La pragmática lingüistica. El estudio del uso del lenguaje, Barcelona, Montesinos, $2^{\mathrm{a}}$ ed., 1994. M. V. Escandell Vidal, Introducción a la pragmática, Barcelona, Anthropos, 1993. S. J. Schmidt, Grundriß der Empirischen Literaturwissenschaft, vol. I: Der gesellschaftliche Handlungsbereich Literatur, Braun schweig-Wiesbaden, Vieweg, 1980. S. J. Schmidt, Kognitive Autonomie und soziale Orientierung. Konstruktivistische Bemerkungen zum Zusammennang von Kognition, Kommunikation, Medien und Kultur, Frankfurt am Main, Suhrkamp, 1994. S. J. Schmidt, Texttheorie. Probleme einer Linguistik der sprachlichen Kommunikation, München, Fink, $2^{2}$ ed., 1976. H. Heinemann/ D. Viehweger, Textlinguistik. Eine Ein führung, Tübingen, Niemeyer, 1991. H. Vater, Einführung in die Textlinguistik. Struktur, Thema und Referenz in Texten, München, Fink, 1992 H. Hörmann, Einführung in die Psycholinguistik, Darmstadt, Wissenschaftliche Buchgesellschaft, $2^{a}$ ed., 1987. C. Knobloch, Sprache und Sprechtätigkeit. Sprachpsychologische Konzepte, Tübingen, Niemeyer, 1994.

${ }^{3}$ C. Lomas/ A. Osoro/ A. Tusón, Ciencias del lenguaje, competencia comunicativa y enseñanza de la lengua, Barcelona, Paidós, 1993, pàg. 27.

¿lbid., pág. 56. Vid. tambièn C. Lomas/ A. Osoro (comps.), El enfoque comunicativo de la enseñanza de la lengua, Barcelona, Paidós, 1993

Vid. a este respecto M. Maldonado Alemán, "Coherencia y textualidad», en Revista de Filologia Alemana, 3 (1995), págs. 163.186. M Maldonado Alemán, «Niveles procesuales en la comprensión textual», en Aspectos de didáctica de la lengua y la literatura, Actas del II Congreso Internacional de la Sociedad Española de Didáctica de la Lengua y la Literatura. ed. de P. Guerrero Ruiz y A. López Valero, 2 vols., Murcia, Universidad de Murcia, 1995, vol. 1, págs. 267-271. M. Maldonado Alemán, «La comunicación lingüistico-textual y el problema de la referencian, en Philologia Hispalensis, 10 (1995).
}
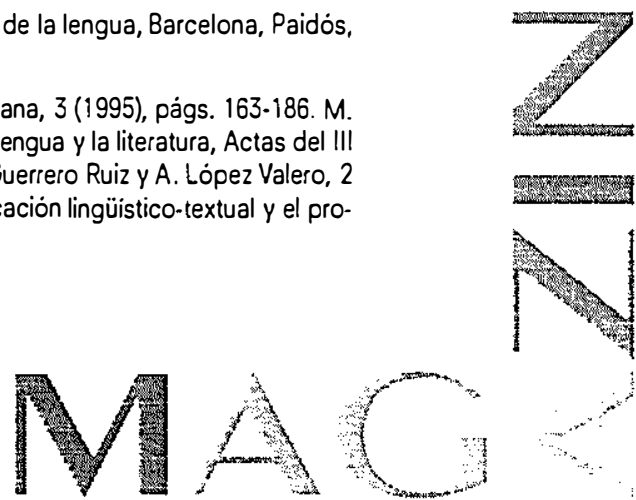
vienen al menos tres variables: el sujeto de la comprensión, la materialidad textual y la situación de recepción 0 interpretación. El sentido finalmente atribuido a un texto resulta de los esfuerzos de los lectores/oyentes por comprender de forma coherente las expresiones lingüisticas, o sea, por hacerlas significativas para ellos mismos, por to que no puede existir un significado o un sentido en un texto, sino exclusivamente para un lector u oyente?.

De aqui se desprende la conveniencia de diferenciar en el proceso de comprensión textual dos dimensiones bien distintas: una, el texto en cuanto realidad de naturaleza material intersubjetivamente identificable; $y$, otra, las estructuras cognitivas que resultan de la asignación del sentido al texto, unas estructuras que $\mathrm{S}$. J. Schmidt denomina comunicado ${ }^{8}$. El comunicado es asi una representación mental significativa de una base textual material en la estructura del saber del receptor; es decir, $\tan$ sólo el comunicado tiene un sentido coherente para el lector.

Asimismo, y por otro lado, en el proceso de comprensión textual habria que distinguir una fase de recepción, que incluye las acciones cognitivas 'internas', y una fase de elaboración, que comprende las acciones comunicativas 'externas'. Todas las actividades cognitivas de consirucción de un comunicado, o sea, las acciones mediante las que un lector otorga un sentido subjetivamente coherente a la materialidad textual, pertenecen a la fase de recepción. En cambio, la verbalización de los resultados de recepción, que se realiza a fin de efectuar una acción de comunicación, pertenece a la fase de elaboración. De aquí se deduce que la elaboración de un texto siempre se realiza en función de la recepción previamente efectuada, por lo que el fundamento de la elaboración textual, en cuanto actividad estrictamente comunicativa que engloba, por ejemplo, la critica e interpretación literarias, no es la materialidad del texto, sino el constructo cognitivo que resulta de atribuirle a ésta un sentido coherente ${ }^{9}$.

En consecuencia, no sólo la recepción, sino también la critica e interpretación textual presuponen siempre la existencia de un sujeto y de un contexto de los que dependen especificamente los resultados comprensivos. $Y$ es por esa razón que la actividad interpretativa, al igual que la receptiva, no puede entenderse como la constatación del sentido único y correcto de un texto, o bien, como el descubrimiento de la verdadera intención de un autor.

$<\ldots>$ bei der literaturwissenschaftlichen Interpretation <handelt es sich> um 'Konstruktion' von Bedeutung. <... Man könnte> sagen, sie formuliere Thesen über mögliche Bedeutung, die Texte im Zusammenhang mit bestimmten Kontexten gewinnen können. Die Frage nach der 'wahren' Bedeutung wird dabei nicht gestellt, weil sie für diese Interpretation irrelevant ist ${ }^{10}$.

El supuesto sentido correcto de un texto sólo se podria indagar si existiera una referencia objetiva fuera del ámbito cognitivo del sujeto, que sirviera de medida imparcial de comprobación. La inexistencia de ese marco objetivo de referencia y la falta, por consiguiente, de una relación de legitimación entre texto e interpretación provocan que los criterios de valoración de una interpretación no sean los de verdad o falsedad, sino los de consenso, plausibilidad e innovación, entre otros. Más que de la constatación del supuesto sentido atemporal y único de un texto, la corroboración de una interpretación es consecuencia de una operación de convencimiento

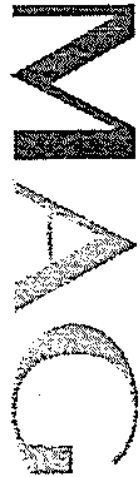

\footnotetext{
¿Vid. S. J. Schmidt, "Text Rezeption Interpretation», en E. Ibsch/ D. H. Schram (eds.), Rezeptionsforschung zwischen Hermeneutik und Empirik, Amsterdamer Beiträge zur neueren Germanistik. 23, Amsterdam, Rodopi, 1987, págs. 23.46, aqui pág. 30.

${ }^{9}$ Vid. R. Viehoff, uRezeption und Verarbeitung. Anmerkur:gen zu methodischen Fragen einer empirischen Literaiurwissenschait:, en SPiEL, 2/1 (1983), págs. 101-121, aqui pág. 102. R. Viehoif, «Literaturkritik als literarisches Handeln und als Gegenstand der Forschung. Hinweise auf Situationsbedingungen und Hanclungskontexte:, ęı Zeitschriit für Literaturwissenschaft und Linguistik (LiLi), 7i (1988), págs. 73-91, aquí pág. 82. R. Viehoif/ M. Burgert, Kommunikatciicinigsprozeß 2. Strukturen und Funktionen deklarativen und orozeciuralen Wissens beim Verstehen von Literatur Untersuchungen zu 'Viërchen' und 'Krimi', LUMiS-Schriiten 29, Universität-Gesamthochschule Siegen, 1991, pág. 7 .

${ }^{\because} \mathrm{H}$. Steinmetz, "Literaturwissenschaftliche Interpretation? „, en E. Ibsch/ D. H. Schram (eds.), Rezeptionsiorscinung zwischen Hermeneutik und Empirik, op. cit. págs. 137-154, aquí pág. i氵2.
} 
social: una interpretación logra finalmente imponerse no porque el texto la legitima y demuestra su 'verdad', sino gracias a su aceptación social por consenso. El grado de aceptación de la interpretación dependerá de su conformidad con las necesidades, convenciones y criterios de valoración de una sociedad dada en un momento determinado.

En consonancia con estos planteamientos, la concepción didáctica tradicional que centra la enseñanza lingüístico-literaria en la transmisión de una interpretación magistral, definitiva y, por supuesto, 'correcta' del texto, carece de justificación. Este modelo didáctico, en su afán por sustituir el texto literario por la correspondiente interpretación fijada de antemano, tiene como consecuencia que, en definitiva, los alumnos no aprenden a leer y comprender el texto, sino más bien la interpretación pertinente. Éstos, careciendo de toda motivación, se contentan con la lectura de la interpretación ofrecida y desestiman el propio texto. De esta manera, profesor y alumno ven limitadas sus funciones a las de intérprete activo y receptor pasivo respectivamente, negándose la posibilidad real de una interacción común.

Planteamos, en consecuencia, la necesidad de evitar una enseñanza centrada en el autor y su intención, o bien, en la transmisión de una interpretación definitiva y 'correcta' de los textos, que reduzca la actividad del alumno a un reproducción fiel de los conocimientos transmitidos. Asumiendo las posiciones teóricas elaboradas, ante todo, por la hermenéutica moderna (M. Frank), la estética de la recepción, la critica recepcional empírica y la ciencia empirica de la literatura, estimamos que la aplicación del texto literario a la enseñanza del alemán como lengua extranjera debe guiarse por una estrategia didáctica que procediendo de un modo inductivo y orientada en el discente asuma la subjetividad del alumno-receptor y estimule una lectura creativa, individual y plural de los textos. Esta concepción:

versucht, um es verallgemeinernd $z u$ formulieren, Literatur der Vergangenheit so zu erarbeiten, daß einmal aus ihr selbst heraus die Beziehungen zur Epoche, der sie entstammt, deutlich werden, die dazu ausgewählten Werke oder Textauszüge so in Intertextualitätsbeziehungen zu stellen, daß aus diesen epochenübergreifende Entwicklungen der sozialen Strukturen oder der Mentalität sichtbar werden, und so thematisch zu gruppieren, daß eine Brücke zwischen der Welt des Textes und der der heutigen Leser geschlagen werden kann".

En el marco de semejante procedimiento inductivo, los alumnos deben tener la posibilidad de desarrollar libremente su disposición para la recepción literaria en virtud de un modelo didáctico de interacción profesor-alumno y alumnoalumno, que permita una forma de trabajo textual cooperativo y activo, y a la vez solidario con el desarrollo individual del discente. Pues, también en la lengua extranjera "geht <es> beim Lesen $<\ldots>$ um das Wiedererkennen eigener Lebenserfahrungen, um die Evokation von Emotionen, persönlichen Phantasien und Wünschen, um die Fähigkeit zur Identifikation"'i2.

La interacción colectiva debe mostrar a los alumnos la posibilidad de constitución de

\footnotetext{
"K. Fingerhut, ulnduktive Literaturgeschichte. Überlegungen zu einer Didaktik der Literaturgeschichte", en FORUM, 6 (1992), Actes del 2n Congrés de l'Associació de Germanistes de Catalunya, ed. de M. Riutort y J. Jané, págs. 94-115, aqui pág. 99.
}

'2I. Mummert, "Literatur im Unterricht Deutsch als Fremdsprache», en Deutsch als Fremdsprache, 2 (1993), págs. $110-111$. 
diferentes variantes de sentido de un texto literario, de sus distintas formas de lectura; asi como también la utilidad y coherencia de éstas. En consecuencia, no se pretende forzar una comprensión aceptada por todos unánimemente. Fundamentalmente, se debe estimular una recepción coherente del texto desarrollada por el mismo alumno partiendo de sus propias posibilidades.

Ese procedimiento metódico, orientado y centrado en el discente, deberá sustentarse en la utilización y activación óptima de las capacidades, conocimientos, intereses y expectativas que éste ya posee con anterioridad a la lectura del texto, y no en sus carencias o deficiencias, tratando de suscitar el gusto por la literatura y la afición a la lectura. Su finalidad ha de estribar en permitir el desarrollo de las habilidades de comprensión lectora del alumno y de su capacidad comunicativa de producción, provocando conocimientos lingüisticos, sociohistóricos, culturales y literarios; o sea, contribuir a la formación de la capacidad comunicativa de recepción y de producción en la lengua extranjera.

Für das Gelingen des Unternehmens ist eine gut durchdachte Progression der Texte unerläßlich; bei einer weniger fortgeschrittenen Gruppe muß sie an das Erlernen neuer grammattikalischer Strukturen gekoppelt sein, oder zumindest so gehalten werden, daß kein Gefühl der Überforderung entsteht. Neben der Grammatik bildet die Erweiterung und Vertiefung des Wortschatzes die zweite Säule des Prozesses; in dieser Hinsicht wird von den konkreten Texten ausgegangen, deren Progression auch von diesem Standpunkt aus festzulegen ist, und dabei wird auf die jeweils frequentesten und relevantesten Elemente hingewiesen $\langle\ldots\rangle^{i 3}$.

Consideramos asi que en la aplicación del texto literario a la enseñanza de la lengua alemana será necesaria la integración de lenguaje y contenido, $e$ incluso un predominio y valoración clara de este último, por lo que desde un principio la explicación de estructuras gramaticales y unidades léxicas debe cumplir una función auxiliar y supeditarse a la comprensión del texto. Consiguientemente, para alcanzar este fin, la literatura "muß nicht mehr die Rolle einer didaktischen Dienerin spielen, sich etwa als bloßen Sprechanlaß, als Landeskunde-Ersatz, als Grammatik-Suchfeld benutzen oder zum reinen Analyse-Objekt <...> degradieren lassen"i4.

En definitiva, el punto de partida de este planteamiento es la consideración del lenguaje como discurso, o sea, como actividad comunicativa de construcción de sentido, donde el núcleo que determina y permite entender el fenómeno comunicativo ya no es el marco oracional, sino el contexto de producción y recepción y los sujetos de la comunicación, esto es, el conjunto formado por factores cognitivos, situacionales y socioculturales. Por ello entendemos que tanto la determinación de los objetivos concretos a alcanzar como la selección de textos y la planificación metódica de la utilización de esos textos se han de adaptar a los presupuestos, intereses y necesidades de los alumnos, asi como también a su competencia lingüistica y lectora'5.

De este modo, con ayuda de una adecuada selección de textos, alejada de una excesiva exhaustividad y ajụstada a criterios de representatividad, en los que la consideración estética no debe primar sobre su función sociocultural, la aplicación del texto literario a la enseñanza de la lengua alemana deberá fundamentarse en la lectura del propio texto $y$ en el conocimiento por parte del alumno de su contexto de producción, para a partir de ahi, una vez constituidos en un nivel individual los diversos significados y sentidos textuales, pasar a un análisis interpretativo a fin de comprobar su plausibilidad y coherencia.

\footnotetext{
13 P. Estelrich, "Zur Verwenciung von Feuilletons im Unterricht. Ein Beispiel anhand zweier Texte von Egon Envin Kisch und Joseph Rçth", en FÖRUM, 6 (1992), Actes del 2n Congrés ce l'Asscciació de Germanistes de Catalunya, op. cit., pảgs. 148-1Ề, açui pág. 149.

"I. Mummert, "Literatur im Unterricht Deutsch als Fremcsprache», op. cit., pág. 110.

"s Vid. G. Bach/ J.P. Timm (eds.), Englischunterricht. Grundlagen und Methoden einer handlungsorientierten Unterrichtspraxis, Tübingen, Francke, 1989.
} 
En consecuencia, aunque la estrategia didáctica que proponemos se sustenta en la subjetividad lectora de los alumnos en cuanto categoria productiva, estimamos necesario evitar que el uso del texto literario quede reducido a la actividad eminentemente espontánea y emocional que caracteriza a las acciones de recepción. A la concretización individual del significado textual deberá seguir, por tanto, una actividad de análisis e interpretación que, partiendo de normas o reglas de procedimiento fijadas de antemano, tenga como finalidad la superación de la espontaneidad de la fase de recepción y la justificación racional de la comprensión individual del texto. En esta fase de interpretación el alumno deberá adquirir las herramientas conceptuales y destrezas que le permitan realizar un análisis crítico del texto. Asimismo se intentará alcanzar en lo posible unos resultados interpretativos intersubietivos ${ }^{15}$, sin perjuicio de que desde un principio se intente garantizar la libre disposición del alumno para la interpretación literaria.

Siguiendo estas ideas generales, proponemos concretamente para el tratamiento del texto literario en la enseñanza de la lengua alemana un modèlo metodológico que abarca cinco fases sucesivas:

1. Una fase de introducción, previa a la lectura, destinada a crear las condiciones necesarias para que el texto pueda ser entendido lingüistica y temáticamente. Aqui se trata de activar el conocimiento ya adquirido por el alumno y también de suministrarle conocimientos adicionales, imprescindibles para la comprensión del texto. Esta fase ha de contribuir, en todo caso, a despertar el interés por la lectura y a evitar el desánimo del alumno ante la posible complejidad del texto.
2. Una fase de recepción en la que se tratará, sobre la base de una lectura lenta y profunda, que el alumno realice una comprensión lectora subjetivamente coherente, libre y autónoma, sin que se le impongan unas normas de análisis especificas o un esquema de procedimiento rigido. Cometido de esta fase "ist Lernen im buchstäblichen Sinn, nämlich Aneignung von sprachlich und inhaltlich Unbekanntem, was selbstverständlich jeder für sich zu tun hat.Es erfordert Arbeit am Text, eigene Arbeit $\langle\ldots\rangle^{17 "}$. Objetivo primordial es que el alumno encuentre placer en la realización de su propia recepción, que extraiga conclusiones que él considere relevantes desde su situación sociocultural e individual, y que tenga deliberadamente en cuenta los componentes emocionales en sus resultados de recepción. En todo momento se ha de evitar en esta fase " $<$ ihm> den Spaß an 'Literatur' durch den verhaßten Zwang zur Interpretation literarischer Kommunikate endgültig zu rauben"18. Asi y todo, ante posibles dificultades en la actividad lectora se podrán explicar en esta etapa ciertas técnicas de lectura, especialmente estrategias de inferencia, que eviten un uso continuado del diccionario y faciliten la comprensión en la lengua extranjera's, pero sin que ello merme el carácter subjetivo de la recepción.

3. Una fase de elaboración, comunicación y discusión de los distintos sentidos atribuidos por los alumnos al texto. Sobre la base de un procedimiento de interacción alumno-alumno y alumno-profesor, los alumnos comprobarán en esta fase las distintas posibilidades y modalidades de construcción de sentido, su coherencia y sus presuposiciones, "und begreifen dadurch auch selbst ihre eigenen Schöpfungen und ihre Intentionen ${ }^{20 \prime \prime}$. Aqui se plantearán cuestiones relativas a la comprensión global y también a la pormenorizada o detallada del texto; a su

\footnotetext{
${ }^{i 6}$ Vid. K. H. Spinner, "Interpretieren im Deutschunterricht», en Praxis Deutsch, 81 (1987), págs. 17-23, aqui pág. 17.

"K. Forssmann/ M. Siguán, "Klassikertexte im Sprachunterricht? Versuch einer Rehabilitierung am Beispiel des Novalis», en G. Ruipèrez (coord.), Homenaje a José Belloch Zimmermann, Cáceres, Universidad de Extremadura, 1989, págs. 53-61, aqui pág. 57.

1a S. J. Schmidt, "Anmerkungen zum Literaturunterricht des Faches Deutsch als Fremdsprachen, en A. Wierlacher (ed.), Fremdsprache Deutsch. Grundlagen und Verfahren der Germanistik als Fremdsprachenphilologie, vol. 2, München, Fink, 1980, págs. 520-524, aquí pág. 521.

: Vid. 8. D. Müller, "Lesestrategien und Verstehensgrammatik. Mögen Schüler Dichtung?", en A. Wolff/ H. Rössler (eds.), Deutsch als Fremdsprache in Europa. Materialien Deutsch als Fremdsprache, vol. 29, Regensburg, 1990, págs. 139-160. 
tema, género, argumento y estilo. Se prestará especial atención a la actividad misma de lectura, al proceso de comprensión lectora "der Vorgang, den jede Textdeutung zur Voraussetzung, zur Bedingung hat $^{2{ }^{21}}$ y a sus condicionantes especificos, y se tendrán en cuenta los componentes emocionales e irracionales. Igualmente, esta fase atenderá a la "möglichst endgültigen Klärung der noch anstehenden Probleme lexikalischer, syntaktischer und stilistischer Art" $^{\prime 22}$.

4. Una fase de análisis e interpretación ${ }^{23}$. Esta fase tendrá como objetivo que el alumno proceda de un modo sistemático y riguroso en el análisis y comprensión interpretativa del texto, tanto en un nivel cotextual como contextual, superando la espontaneidad de las etapas de recepción y de elaboración. Es una fase destinada a una sistematización y justificación racional de la comprensión individual, o sea, de las estrategias subjetivas de constitución de sentido y de las acciones de verbalización, utilizando unos procedimientos de análisis explicitos que permitan conseguir una precisión y rigor adecuados. Ello impedirá "daß <beim Textverstehen> einem extremen Subjektivismus Tür und Tor geöffnet werden. <... Denn $>$ die Achtung vor einem bedeutenden literarischen Text gebietet es, ihn nicht willkürlich auslegen zu lassen und ihm sozusagen ein Unsinnpotential zu unterstellen $\langle\ldots . .\rangle^{\prime \prime 2}$. En esta fase tendrán cabida cuestiones referentes a la localización y tipologia textual; formas de expresión; género de discurso; micro y macroestructuras; tipo de conectores; relación tema-rema; focalización, modalidad, temporalización y espacialización; polifonia enunciativa; aspectos estilisticos, retóricos, metafóricos, etc. ${ }^{25}$; asi como también informaciones relativas al contexto socio-cultural y literario del texto. Además, "<hier> soll bereits zu einer kritischen Stellungsnahme hinleiten"zб.

5. Y, por último, una fase de aplicación, comprobación y afianzamiento de los conocimientos adquiridos. Ante todo, esta fase está dirigida a potenciar la competencia productiva y capacidad creativa del alumno, o sea, a fomentar la utilización libre de la lengua extranjera, también en su uso literario ${ }^{27}$.

En suma, entendemos que el texto literario puede ser el punto de partida y de llegada de la enseñanza de la lengua alemana, una consideración que a nuestro juicio, desde las reflexiones expuestas en

\footnotetext{
"D. Krusche, Aufschluß. Kurze deutsche Prosa im Unterricht Deutsch als Fremdsprache, Teil II, op. cit., pág. 21.

${ }^{2}$ K. Forssmann/ M. Siguán, "Klassikertexte im Sprachunterricht? Versuch einer Rehabilitierung am Beispiel des Novalis”, op. cit., págs. 57-58.
}

${ }^{23}$ Sobre la problemática inherente a las operaciones de análisis e interpretación, vid. O. Jahraus, «Analyse und Interpretation. Zu Grenzen und Grenzüberschreitungen im struktural-literaturwissenschaftlichen Theorienkonzept", en Internationales Archiv für Soziaigeschichte der deutschen Literatur, 19/2 (1994), págs. 1-51.

${ }^{24} \mathrm{~K}$. Forssmann/ M. Siguản, "Klassikertexte im Sprachunterricht? Versuch einer Rehabilitierung am Beispiel des Novalisn, op. cit., pág. 59.

${ }^{25}$ Vid. a este respecto H. F. Plest, Textwissenschaft und Textanalyse. Semiotik, Linguistik, Rhetorik, Heidelberg, Quelle \& Meyer, $2^{\mathrm{a}}$ ed. 1979. H. F. Plett, Einführung in die rethorische Textanaiyse, Hamburg, Buske, $8^{a}$ ed., 1991. L. A. Acosta, Cuestiones de lingüistica textual. Con una selección bibliográfica, Salamanca, Universióac de Salamanca, 1982. L. A. Acosta, „Fundamentos lingüístico-comunicativos del texto literario tw, en Revista de Filologia Alemana, 2 (1994), págs. 13.42. J. M. Pozuelo Yvancos, Teoria del lenguaje literario, Madrid, Cátedra, 1988. J. Lozano/ C. Peña-Marin/ G. Abril, Anälisis del discurso. Hacia una semiötica de la interacción textual, Madrid, Cátedra, $3^{a}$ ed., 1989. K. Brinker, Linguistische Textanalyse. Eine E:nüürung in Grundbegriffe und Methoden, Berlin, Erich Scrimidt, $2^{a}$ ed., 1989. K. Brinker (ed.), Aspekte der Textlinguistik, Hildesheim-Züricin-New York, Olms, 1991. K Brinker, Textlinguistik, Heidelberg, Groos, 1993. H. Heinemann/ D. Viehweger, Textlinguistik. Eine Einführung, op. cit. W. Klein (ed), Textlinguistik, Göttingen, Vadenhoeck \& Ruprecht, 1992 H. Vater, Einführung in die Textlinguistik. Struktur, Thema und Referenz in Texten, op. cit. M. Titzmann, Strukturale Textanalyse. Theorie und Praxis der Interpretation, München, Fink, $3^{a}$ ed.. 1993. O. Jahraus, "Analyse und Interpretation. Zu Grenzen und Grenzüberschreitungen im struktural-literaturwissenschaftlichen Theorienkonzes:y, op. cit.

${ }^{35}$ K. Forssmann/M. Siguản, "Klassikertexte im Sprachur:erricht? Versuch einer Rehabilitierung am Beispiel des Ncvalis», op. cit., pág. 58.

"Sobre las distintas propuestas existentes para la ac:ic sción de lo expuesto en esta fase vid. J. Collie/ St. Slater, Literature in the Language Classroom, Cambridge, CUP, 1987. K. Forssmarriv M. Siguản, "Klassikertexte im Sprachunterricht? Versuch einer Rehabilitierung am Beispiel des Novalis”, op. cit. págs. 58-59. W. Bruscn, „Vom Lesen zum Schreiben: Dependent Autorship. Kreative Schreibarbeiten als alternative Textarbeit», en FU, 26/1 (1992), págs. 46-54. G. Rupp, "Literarische Eriahrung und histórisches Verstenen durcn Schreiben zu und Interpretieren von Texten. Am Beispiei der Erercesing mit Hofmannsthal 'Terzinen' '», op. cit. 
este trabajo, supone el reconocimiento de la subjetividad lectora de los alumnos como una categoria productiva y necesaria en el proceso de aprendizaje. Por esa razón la opción didáctica que proponemos está dirigida a la formación y desarrollo de la competencia comunicativa del alumno, una competencia que incluye no sólo la competencia lingüistica (en el sentido chomskiano) sino también la competencia pragmática ${ }^{28}$.
De este modo, la utilización del texto literario en la enseñanza del alemán como lengua extranjera aparece doblemente justificada: por un lado permite superar una enseñanza de la lengua centrada en la frase y en su sintaxis $y$, por otro, posibilita la consideración e inclusión deliberada del sujeto del aprendizaje en la enseñanza misma, lo que motivará que ésta se constituya, en definitiva, en un proceso de interacción comunicativa.

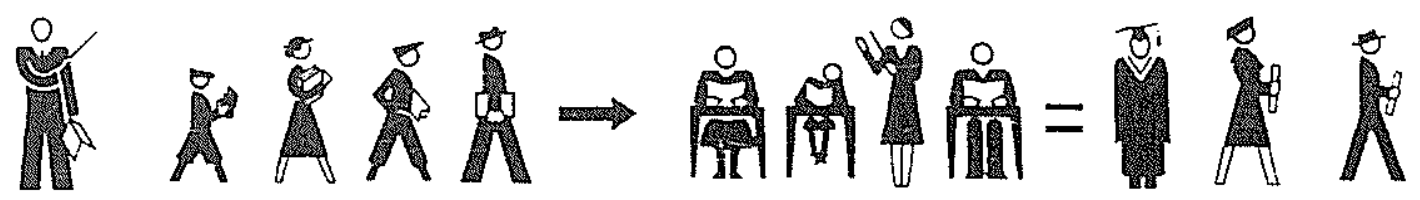

(c)

\footnotetext{
¿s Vid. W. Edmonson, Spoken Discourse. A Model for Analysis, London, Longman, 1981. Dell H. Hymes, Vers la competénce de communication, Paris, Hatier, 1984.
} 